\title{
A Vision of Re-distributed Manufacturing for the UK's Consumer Goods Industry
}

D. Bessière ${ }^{1}$, F. Charnley ${ }^{2}$, A Tiwari ${ }^{3}$, M.A Moreno*

${ }^{1}$ Centre for Competitive Creative Design, Cranfield University, Cranfield, UK. dorothee.bessiere@gmail.com

${ }^{2}$ Centre for Competitive Creative Design, Cranfield University, Cranfield, UK. f.j.charnley@cranfield.ac.uk

${ }^{3}$ Department of Automatic Control and Systems Engineering, the University of Sheffield Mappin Street, Sheffield, S1 3JD.

a.tiwari@sheffield.ac.uk

* Centre for Competitive Creative Design (C4D), Cranfield University, College Road, Cranfield, MK43 OAL, UK. m.moreno@cranfield.ac.uk 


\section{A Vision of Redistributed Manufacturing for the UK's Consumer Goods Industry}

The linear production of consumer goods is characterised by mass manufacture, multinational enterprises and globally dispersed supply chains. Redistributed manufacture (RDM) is an emerging topic, which seeks to enable a transition of the current linear model of production and consumption, by taking advantage of new technologies. This paper aims to explore the challenges, opportunities and further research questions to set a vision of Redistributed manufacturing for the UK's consumer goods industry. To set this vision, a literature survey was conducted followed by a qualitative enquiry where PESTLE ${ }^{1}$ aspects of RDM were analysed. This analysis was interpreted through a roadmap. As a result of this roadmap, four RDM characteristics (i.e. customisation, use of digital technologies, local production, and the development of new business models) were identified. These characteristics helped to set the future vision of RDM in the UK's consumer goods sector.

Keywords: (Re) Distributed Manufacture, Consumer Goods Industry,

Customisation, Digital Technologies, Business Models, Local Production.

\footnotetext{
${ }^{1}$ Political, Economic, Social, Technological, Legislative, Environmental
} 


\section{Introduction}

The consumer goods industry has been characterised by large-scale manufacturing sites, with centralised operations (Srai et al. 2016). Over the last three decades, globalisation has influenced this industry to develop centralised systems with manufacturing processes far from the point of consumption, making its growth based on building capacity and markets on a global scale (Chatterjee et al. 2010). For the purpose of this research, the classification of the consumer goods sector provided by the Euromonitor International Database ${ }^{2}$ was used which includes the following sub-sectors: Beauty and personal care, consumer appliance, consumer electronics, home and garden, home care, food and drink, personal accessories, toys and games, wearing apparel and footwear. The manufacturing sector of consumer goods in the UK makes a topical focus of study through which to understand the opportunities and challenges of a redistributed model of production and consumption. This is because, in recent years, some sub-sectors (e.g. consumer appliances, consumer electronics, home and garden, toys and games, personal accessories, wearing apparel and footwear) have rapidly declined, whilst others (e.g. food and drink, home care, and beauty and personal care) have their operations centralised and run by large multi-national companies (Foresight 2013). To explore the possibilities of redistribution of the consumer goods sector in the UK, it is important to understand what redistributed manufacturing $(\mathrm{RDM})$ means.

Current research on the topic of RDM has multiple definitions. For example, Pancost and McMahon's (2015) definition is focused on small-scales and local manufacturing while, Freeman's et al. (2016) define RDM as a model that introduces the customer to the production process to answer their demands, by enabling the

\footnotetext{
${ }^{2}$ http://www.euromonitor.com/
} 
resilience of production systems. For Moreno and Charnley (2016), the focus is more on the decentralisation of manufacture with the aim to create a connected production and consumption system that takes advantage of newly emerging technologies to allow local production of goods that meet global demands. In addition, other scholars on the topic advocate that current manufacturing systems could be decentralised by current technological developments in engineering and computing, which could bring new capabilities in terms of automation, complexity, flexibility and efficiency (Srai et al. 2016, Matt et al. 2015). As demonstrated there still isn't a clear definition of what RDM really means. Srai et al. (2016) have conducted the most recent literature survey and argue that the literature in the topic is fragmented as it attempts to demonstrate its applicability in a wide variety of sectors and contexts. Therefore, this paper aims to address this gap by examining challenges, opportunities, and further research questions that could help to set a vision of RDM in a specific sector and context, taking the UK's consumer good industry as an example.

\section{Enquiry design and methods}

To set a vision of RDM for a specific context such as the UK's consumer goods sector, the following five steps were undertaken, as shown in Figure 1 and further explained in the next sub-sections of this paper.

The methodology followed was based on a literature review survey and on an enquiry design to gather data from experts' opinions from different backgrounds (i.e. industry experts, academics, and policy influencers) to set up a vision of RDM in the consumer goods sector. 


\begin{tabular}{|c|c|c|}
\hline Step 1 & Step 3 & Step 5 \\
\hline $\begin{array}{l}\text { Literature Survey and three } \\
\text { workshops to understand the } \\
\text { current situation within the } \\
\text { consumer goods industry and } \\
\text { its emerging trends. }\end{array}$ & $\begin{array}{l}\text { Analyse data collected to } \\
\text { validate through nine } \\
\text { interviews with experts. } \\
\text { Analysis and triangulation of } \\
\text { all data. }\end{array}$ & $\begin{array}{c}\text { Synthesis of } \\
\text { data into a } \\
\text { Roadmap. }\end{array}$ \\
\hline
\end{tabular}

Figure 1 Enquiry design and methods

A qualitative approach to data analysis was chosen to deeply analyse the data collected and come up with new and unexpected outcomes. Data was analysed by following a thematic coding approach. This type of analysis is mainly used in a qualitative enquiry as "a constructionist method, which examines the ways in which events, realities, meanings and experiences, or the effects of a range of discourses are operating within society" (Robson 2002). Finally, to synthetize the outcomes, the data was collated using a roadmap which describes the way the consumer goods industry will move forward through the next decades. A roadmap provides a consensus view or a vision of the future through a specified timeline, which informs decision makers. A road mapping process was selected as it provides a way to identify, evaluate, and select strategic alternatives that can be used to achieve a desired objective (Kostoff and Schaller 2001). An expert-based approach was followed in which specialists' opinions are considered to identify and develop attributes for the roadmap (Kostoff and Schaller 2001).

\section{Step 1: Literature review survey}

A literature review was conducted focusing on exploring:

- The current situation of the UK's consumer goods industry situation to define the possible challenges of a redistributed model of production and consumption in the UK's consumer goods sector. 
- The emerging trends in current production and consumption systems, to identify the future opportunities for RDM within the UK's consumer goods industry.

To conduct the literature survey, the following academic databases were used: Scopus, Google Scholar, EBSCO Information Services Host, and ProQuest. Keywords included (UK) *manufacture, *consumer goods sector, and *(re-)distributed/decentralisation/localisation, plus *customisation, *digital technology, *sustainability, *innovation. The literature searches generated articles on conceptualising Redistributed manufacture by determining its emerging trends (Table 1). However, through the literature survey, little information was uncovered specifically concerning the UK's consumer goods sector. This was further explored in Step 2.

Table 1 Emerging trends of Redistributed manufacture according to the literature survey

\begin{tabular}{|l|l|}
\hline Emerging Trends & Authors \\
\hline Decentralisation/localisation & $\begin{array}{l}\text { Matt et al. 2015, Srai et al. 2016, Rauch et al. 2015, 2016, } \\
\text { Fox 2014,2015, Mourtzis and Doukas 2013, Pancost and } \\
\text { McMahon 2015, Freeman et al. 2016, Foresight 2013, } \\
\text { OECD, 2016. }\end{array}$ \\
\hline Customisation & $\begin{array}{l}\text { Mourtzis and Douka 2014, Moreno and Charnley 2016, } \\
\text { Kohtala 2014, Fogliatto et al. 2012, Gandhi and Gervet } \\
\text { 2016. }\end{array}$ \\
\hline Technological Development & $\begin{array}{l}\text { Gao et al. 2015, Kang et al. 2016, Malak et al. 2016, } \\
\text { Manyika et al. 2015, Smith 1992, Verma et al. 2016, } \\
\text { Birtchnell and Urr, 2016, Baur and Wee 2015, Nanterme } \\
\text { and Daugherty 2016, Gibson et al. 2014, Kietzmann et al. } \\
\text { 2014, Liu et al. 2014. }\end{array}$ \\
\hline Sustainability & $\begin{array}{l}\text { Matt et al. 2015, Kohtala, 2014, Kohtala and Hyysalo 2015, } \\
\text { Rauch et al. 2015, 2016, Zanetti et al. 2015, DeVor et al. } \\
\text { 2012, Liu et al. 2014, Moreno and Charnley 2016, Fox } \\
\text { 2015, Garetti and Taish 2012, Beamon and Fernandes 2004, } \\
\text { Genovese et al. 2014. }\end{array}$ \\
\hline Open Innovation & $\begin{array}{l}\text { Kohtala 2014, Kohtala and Hyysalo 2015, Dickens et al. } \\
\text { 2016, Prendeville et al. 2016, Vega-Jurado et al. 2015, } \\
\text { Waller and Fawcett 2014, Fox 2014, Romero and Molina, } \\
\text { 2011. }\end{array}$ \\
\hline
\end{tabular}

\section{Step 2: Three workshops}

Alongside the literature survey, three workshops were conducted to reveal information surrounding the current situation within the UK consumer goods manufacture industry 
and its future trends. Specifically, through the workshops, the researchers explored opportunities, challenges and research questions for the UK's consumer goods sector. A brief description of these workshops is presented below.

(1) Opportunities and challenges of RDM within for the UK's consumer goods sector - Version 1\&2: Two workshops were conducted at different times. The first workshop was held on $3^{\text {rd }}$ June 2015 followed by a second workshop on $9^{\text {th }}$ March 2016. Both workshops were in London, and, 80 participants attended in total. Participants, who attended, had different backgrounds and expertise on the consumer goods sector; including 35 industry experts, 35 academics, and 10 policy influencers. The aim of the workshops was to capture challenges and opportunities of Redistributed models of production and consumption for different sub-sectors of the UK's consumer goods industry. Participants were divided in mixed groups of 6 to 10 people. Each group was given a product from the sub-sectors of the consumer goods industry and three main questions were used to drive the discussion, these were:

- What would an RDM model of production and consumption look like for the product you were given?

- What are the challenges and opportunities of implementing a Redistributed model of production and consumption?

- How could emerging technologies assist in enabling the alternative RDM model your group has developed?

(2) Setting the vision of RDM for the UK's Consumer Goods Sector: This was a 2day workshop with 31 participants which aimed to start setting the vision of RDM for the UK's consumer goods sector. Through a series of activities, 6 
participants from industry, 3 participants from non-profit organisations and 22 participants from universities, split into mixed groups to express their ideas about RDM, and identify current and future opportunities and challenges for the consumer goods sector. Then, a roadmap with an initial vision of RDM was built by following a PESTLE (Political, Economic, Social, Technological, Legislative, and Environmental) Analysis.

\section{Step 3 Synthesis and analysis of the literature review and workshops}

Findings from the literature were used to understand the current situation within UK consumer goods manufacture and to understand the emerging trends that conceptualise RDM. These trends were used as 'themes' to analyse the data from the workshops following a "thematic coding approach" explained in more detail in Step 5. The data from the workshops (https://doi.org/10.17862/cranfield.rd.4746898.v1) was synthesised and further analysed through a PESTLE Analysis, to capture challenges, opportunities and possible research questions to set the future vision of RDM. To further validate or refute the initial findings, further interviews with experts were conducted.

\section{Step 4 Semi-structure interviews}

In total nine semi-structure interviews were conducted with 6 experts from industry with knowledge on the UK's consumer goods industry and 3 academics with expertise across manufacturing systems. Table 2 shows a description of the experts interviewed.

Table 2 Experts from industry and academia interviewed

\begin{tabular}{|l|l|}
\hline Role & Company / University \\
\hline Leader Industry for Change (Industrial Innovation) & Cisco \\
\hline Director responsible for strategy and futures & Centre for Process Innovation \\
\hline Innovation and Manufacturing Director & Unilever \\
\hline Chief Executive & $\begin{array}{l}\text { Greater Manchester Chamber } \\
\text { of Commerce }\end{array}$ \\
\hline
\end{tabular}




\begin{tabular}{|l|l|}
\hline Editor in Chief & Circulate Magazine \\
\hline Director of Consulting & The Clearing \\
\hline $\begin{array}{l}\text { Research Fellow at the Centre for Resource Efficient } \\
\text { Manufacturing Systems }\end{array}$ & Teesside University \\
\hline $\begin{array}{l}\text { Professor of Innovation Management and Policy } \\
\text { Professor of Manufacturing Informatics }\end{array}$ & University of Manchester \\
\hline
\end{tabular}

Semi-structured interviews were chosen to allow more flexibility in exploring the topic in question (Robson 2002). The interviews were tailored for each interviewee but in general, questions concerned the consumer goods industry's motivations to move towards RDM models in large and small medium enterprises (SMEs), the role of legislation, the role of end-users, the current challenges and opportunities of the transition to RDM, the application of new technologies, and the environmental impacts of RDM.

\section{Step 5: Synthesis and development of a roadmap to present the future vision of redistributed manufacturing for the UK's consumer goods sector}

The data (https://doi.org/10.17862/cranfield.rd.4746901.v1) from the steps above was analysed following a thematic coding approach to examine the ways in which events, realities, meanings and experiences of participants that took part in this enquiry, could inform a vision of RDM for the consumer goods sector. The thematic analysis conducted was the following:

- Data familiarisation,

- Code generation regarding the identified opportunities, challenges, and possible research questions,

- Identification of common themes through a PESTLE analysis following the identified trends in the literature survey, 
- Triangulation of all data to validate the analysis and ensure consistency. This triangulation was depicted on a roadmap of the current (2016) near (2025) and distant (2035) trends of RDM in the UK's consumer goods industry.

\section{Findings and analysis}

\section{Literature review findings}

The UK currently centralises the major part of its consumer goods production in China, India and Bangladesh. This generates an important instability in the global economy and has impacted UK manufacturing with a decrease of $0,5 \%$ and a deficit of $£ 12$ bn in 2015 (OECD 2016).

The UK Government acknowledged this current situation. As such, they launched the Foresight Report (2013) in which they state that the redistribution of production and consumption could help manufacturing systems to be faster, more responsive, closer to the consumer, and more sustainable. Through the literature survey, five key trends were identified that could enable the redistribution of manufacturing systems for the consumer goods sector:

- Localisation: RDM is about decentralising one or more activities of the value chain, from the extraction of raw materials to the fabrication and distribution, so the final product is manufactured closer to the final user (Srai et al. 2016). The proximity between companies and customers is considered as an important factor for success of distributed models of production and consumption (Rauch et al. 2015). Localisation can also include the distribution of movable factories, in the form of mini-factories that are the size of a van that can move daily or weekly according to the changes in demand and the surrounding conditions (Fox 2015). However, localisation could face certain challenges. For the 
manufacturer, this includes re-thinking the way in which products are fabricated and assembled, adapting to changes that could enable a fully flexible and efficient manufacturing processes, and achieve efficient cross-functional communication with their suppliers and customers (Matt et al. 2015). Other challenges include the impact on regulation and policies. Even if the major political decisions remain central, RDM will allow more responsibility at a regional scale (OECD 2016).

- Customisation: The demand for personalised products is increasing (Mintel 2016). Customers are no longer satisfied with mass produced items and are now looking for personalised products and services according to their own needs (Gandhi and Gervet 2016). For companies, the opportunities of investing in customised products are: to increase their profits in the long term by understanding their consumers better, increase their brand equity and improving their relationship with their customers (Moreno and Charnley 2015). A more efficient customization process could be enabled if an unlimited variety of products that could be made locally (Mourtzis and Douka 2014), using local materials (Fogliatto et al. 2012), and optimising production to be made on demand, avoiding over-stock of products (Kohtala 2014).

- Technological Development: Emerging technologies such as automation and robotics, big data analytics, the Internet of Things (IoT), additive manufacturing, cloud computing, mobile technologies, social networks, and modular design amongst others; can support the transition towards a more connected decentralised manufacturing systems (Gao et al. 2015, Kang et al. 2016, Malak et al. 2016, Manyika et al. 2015). Current technology had seen great advances in human-to-machine communication systems. These advances are evolving 
towards a complete digital system through machine to machine (M2M) learning (Verma et al. 2016). This new forms of intelligence could help to increase revenue and competition in the consumer goods sector. However companies would need to adjust their business models, production and marketing plan to account for all benefits. Some of the foresee benefits of this digital transformation are: positive environmental and economic impacts as technology could help to reduce the use of resources (Birtchnell and Urr 2016), improved relationships with end-users, and improved delivery of products in a more responsive time (Baur and Wee 2015). To be able to adjust to the changes caused by advances in technology, the consumer goods industry would need to set in place new production management systems (Smith 1992). In addition, policy and regulations will have a key role to play to enable better control on how data is used and distributed, as well as implementing measures to create digital trust (Nanterme and Daugherty 2016).

- Sustainability: Current advocates of RDM (Matt et al. 2015, Kohtala 2014, Kohtala and Hyysalo 2015, Rauch et al. 2015, Zanetti et al. 2015, DeVor et al. 2012), have considered how small-scale, flexible manufacturing networks could enable environmental benefits leading to more sustainable forms of production and consumption. Genovese et al. (2014) recognise some of the challenges to implement a sustainable supply chain in the consumer goods sector. As such, it is argued that RDM could enable more sustainable supply chains by reducing emissions (Matt et al. 2015, Rauch et al. 2015) and by recovering materials (Beamon and Fernandez 2004, Kohtala 2014, Kohtala and Hyysalo 2015) as a result of shorter supply chains. RDM could also help in better resource management through implementing energy-efficient and resource-saving 
manufacturing systems (Malik et al. 2011, Srai et al. 2016), and could result in improved use of resources and materials through enabling recovery and recycling (Manyika 2012).

- Open Innovation: RDM offers an opportunity for open innovation due to closer interaction between the consumer, designer and producer in which co-creation is enabled by shared knowledge (Srai et al. 2016). With open innovation, products can be introduced into the market at a faster rate (Waller and Fawcett 2014).

RDM models are also characterized by a system in which the production becomes part of the consumption process called 'prosumption' (Kohtala 2014). 'Prosumers' can contribute to the design process, allowing a greater customization and personalization of products and services (Kohtala and Hyysalo 2015). It is foreseen that open innovation will enable the creation of connected spaces where access to relevant knowledge and skills will be key to move towards a Redistributed model of production and consumption (Dickens Kelly and Williams 2013, Prendeville et al. 2016). The consumer goods industry will need to adapt to this connected transformation by radically modifying their facilites for flexible production systems, as well as addressing customer dynamics to undestand changing needs and preferences and, to improve opportunities for co-creation (Romero and Molina 2014).

\section{Workshop findings}

The contrasting opinions of the different workshop's participants are reported below and categorised under the five trends found in the literature review (i.e. localisation, customisation, technological development, sustainability, and open innovation). A full summary of these results can be found in 
https://doi.org/10.17862/cranfield.rd.4746898.v1.

- Localisation: participants from the 'Opportunities and Challenges of RDM for the UK's Consumer Goods Sector' workshop, pointed out that RDM models could be challenging due to the speed and efficiency of current mass production manufacturing systems. Nonetheless, it was acknowledged by participants of the 'Setting the vision of RDM for the UK's Consumer Goods Sector' workshop, that RDM models offer an enhanced local, connected, smart factory concept that could be present in different locations. This model could enable production with local materials, as well as a more flexible production system that adapts to consumers' demands. Despite this, academics from the same workshop argued that the term 'local' remains debatable as they wondered whether small-scale production could create higher value, as they see the existing infrastructure as a challenge. Participants from all workshops raised the question: "What is redistributed?" acknowledging that it is difficult to define the expanse of localisation of RDM, as certain areas of manufacture would still need to be centralised do to economies of scale.

- Customisation: Participants from all workshops acknowledged that customisation is currently a trend within the consumer goods sector. However, most participants acknowledged that the consumer benefits associated to customise products are still unclear. Participants from the first version of the 'Opportunities and Challenges' workshop considered that a customised product could be 10 per cent more expensive than a regular product. Hence, it is important to understand if customers are willing to pay more for these. On the other hand, most participants mentioned that customisation could increase customer loyalty and improve brand value. 
- Technological development: From the discussions across the three workshops the main challenges identified were: security regarding data management, and the learning process to understand which data is useful to make strategic decisions within a business. The main opportunities identified for the consumer goods sector were: the use of data as a new currency and the development of enhanced skills on science, technology, engineering and mathematics (STEM), to foster employment in these areas.

- Sustainability: Merging services within the manufacturing process were considered in all workshops as an opportunity for RDM to boost sustainability. However, participants questioned if "RDM could increase or reduce environmental impacts?" Participants of the three workshops saw opportunities to include services that enhance, re-use, repair and maintenance, but also wondered if more localised manufacturing units could result in higher consumption of resources.

- Open innovation: Participants from all workshops acknowledged that RDM could facilitate co-creation, co-design and co-production within the consumer goods sector. However, the benefits could be countered productive as open sourced forms of manufacture could create more competition with SMEs in local areas. Open Innovation was also related to the use of new technologies and data. Thus, participants raised the questions: "who owns the data? And what is the value of the data collected through open source platforms?"

\section{Interview findings}

In general, the interviews helped to capture some of the missing topics described in the workshop findings, to define the plausible transition to an RDM model for the consumer 
goods sector. For example, the interviews revealed the different opinions concerning the customisation and possible 'prosumption' patterns in RDM. They also pointed out the advantages and drawbacks of mass and local production, and defined a possible transition to RDM within the consumer goods sector. A summary of these findings is presented below.

- Customisation and open innovation - different points of view: Different opinions were raised concerning co-design and co-production through open innovation platforms. Industry experts believe that customers take a greater role in the design of the product. Five interviewees ( 4 from industry and 1 academic) expressed that customisation could help to better meet customers' needs.

However, according to two industry experts this will have to be at the expense of charging consumers more than a basic product. According to one industry interviewee some customers are already prepared to pay more, in exchange for having premium access to products and services. Other interviewees (1 academic, 1 industrial expert) expressed that large consumer groups will still not prepared to pay more, as price is the most important factor in consumers' buying process. However, there was a consensus that there is a demand for new ways to interact with producers like Open Desk ${ }^{3}$, as this model satisfies customers' desires. On the other hand, academics believe that customers still need an intermediary to help them to create their products. For instance, they expressed that in the furniture industry, it is unclear as to whether customers have the ability to design their furniture with local skills and materials.

\footnotetext{
${ }^{3}$ Furniture Company where customers have access to a file to customise their piece of furniture, to then being produced locally.
} 
- Mass production vs. local production: All interviewees agreed that RDM has the capacity to change the way products are made in the consumer goods industry. However, there were views from two academics that the transition would be slow as "things will still be made and transported half way around the world". Despite this, according to one industrial interviewee, there is a trend that customers are willing to buy products made in the UK. It was mentioned by several interviewees ( 3 academics, 2 industrial experts) that this will improve the manufacturers' relationship with customers and will make service models easier to implement. However, an academic expressed that this will require the right infrastructure. Finally, an academic explained that 'local' might have different interpretations in developing and developed countries. "In the UK industries want to be geographically close to the customers whereas in India, they want to be close form a communication point of view." Meaning that in India, manufacturers would like to keep producing for local and global demands, by keeping track of new consumer trends, through using big data and emerging technologies.

- Transition from the current model to a RDM model: All interviewees acknowledge that an experimental phase of RDM is happening, and that to make a transition to RDM plausible, a huge amount of research in innovation is needed. It was acknowledged by an academic and an industrial expert that the ease to move to RDM in the consumer goods sector will depends mainly on the company size, the nature and complexity of the products, the taxes applied in the factory's location or the level of advancement of the technologies used. An industry expert said, "Companies are mainly unsure about such a change and are struggling with digitalisation. But, they are keen to learn more about RDM.” 
Furthermore, two interviewees ( 1 academic, 1 industry expert) agreed that RDM is not applicable for complex products made of complex parts (e.g. electronics), as there are a huge number of key processes, and materials to consider. But they also acknowledged that factories making a simple product could save time and money by producing some parts using robotics and automation. Finally, and industrial expert pointed out that "for simple and cheap products, like bread, RDM would not add any value."

\section{Synthesis and interpretation - RDM roadmap for the UK's consumer goods sector}

The RDM Roadmap contains the identified opportunities, challenges and possible research questions for each identified trend, to further set the vision of RDM for the UK's consumer goods sector. It follows a PESTLE Analysis to cover the impacts of RDM holistically (https://doi.org/10.17862/cranfield.rd.4746901.v1). This information was organised along a timeline, defined through data analysis. The roadmap (https://doi.org/10.17862/cranfield.rd.4746901.v1) shows the current (2017), near (2025) and distant (2035) challenges, opportunities, and possible research questions of RDM in the UK's consumer goods industry, for each aspect of the PESTLE Analysis, as discussed below.

\section{Political Aspects}

Political aspects define the stability of the political environment considering the shift to RDM (Srdjevic, Bajcetic and Srdjevic 2012). As the UK is based on a free market principle, politicians do not have a direct impact on the transition to RDM. However, they can have an impact on the transition through their influence in businesses and society in general (Sternberg 2015). The main challenges, opportunities and research 
questions identified based on political aspects are described below.

- The decentralisation of the consumer goods sector in the current timeframe (2017) could offer opportunities to invest in abandoned areas within a city and stablish a tax-free incentive to occupy these areas. Localisation of manufacturing systems could drive new policies and tax mechanisms for better use of resources (i.e. water, energy and materials).

- In the near future (2025), if technology continues to develop at this fast rate, a challenge will be to adapt current legislation to the new technologies and the use of the data captured by these technologies. Localisation will offer opportunities to set new regulations concerning exchange of goods between countries. However, a challenge would be to set control for local and national decisions. Other political opportunities in the near future will be to develop a new set of policies for small and medium enterprises as well as start-ups, increase political responsibility at a regional scale as well as generate new jobs.

- In the distant future (2035), the localisation of manufacture has the opportunity to bring businesses and citizens closer and act as key enablers of change in their local area. However, the question still remains if cities and organisations are likely to anticipate long-term changes or is likely to react to short-term political shocks.

\section{Economic Aspects}

The economic impacts are related to the economic growth of the country, the unemployment rate and the cost of resources (Roos and Bauwens 2016). In a redistributed model of production and consumption, impacts will mainly result from local production and better relationships with customers. RDM could change the way 
current business is undertaken, and how materials are being sourced and used. In addition, views on how large and small regions are perceived could also change. The main opportunities, challenges and possible research questions identified for the impacts that RDM could have in the economy are described below.

- In the current timeframe (2017), technological developments will offer an opportunity to increase competition, as technology companies will have the ability to generate more consumer insights, giving them the means to accelerate the understanding of customer needs and demands in a more responsive way. The consumer goods sector is currently seeing a transition towards more customised goods. Despite this, justifying higher prices is sometimes a challenge for some sub-sectors of the consumer goods industry, especially for the fast-moving sector, where retaining customers and attracting new ones is based on a pricing mechanism. Localisation and technology could enable better customisation of products by having shorter supply chains, which enable reduction in delivery time. However, a challenge for the consumer goods industry is the better integration of connected and smart supply chains through the use of technology. Other challenges include the adaptation of new production and assemble processes to more localised factories as well as the impact large organisations could have on small communities of producers. Thus, some questions still persist in terms of which processes should be redistributed in terms of economic viability and if it is really worth for a large company to invest in redistributed models of production and consumption.

- In the near future (2025), technological advances could bring economic opportunities as products might be designed for modularity, improving the flexibility in production systems as well as being able to recover high value 
materials. Modularity in product design could facilitate reuse and recycling, bringing economic benefits for these activities, especially if they are undertaken in regional locations. The near future will see an increased domestic economy driven by localised enterprises. However, some challenges will need to be overcome, such as meeting financial requirements (e.g. survival of these enterprises). Questions are raised to drive a redistributed economy, such as: a) what are the economic issues that would need to be overcome in terms of the future labour markets, innovation and land use planning, $b$ ) is there a real value added by shifting the economy to localised manufacturing units through the development of new business models and organisational structures.

- In the distant future (2035), technological advances could bring opportunities to drive automation in manufacturing systems through robotics and IoT. However, these advances could be seen as a challenge as they may impact on jobs and raise affordability concerns for small enterprises. There are also opportunities to use data as a currency as well as have a better accountability of materials. In the distant future, the industry will see a shift from selling physical products to digital ones. This could be seen as an opportunity to generate new business. However, this faces challenges such as how to establish pricing mechanisms to sell services instead of products, which leads to the question on how to demonstrate economic sustainability through this shift.

\section{Social Aspects}

Social aspects refer to the impacts on population, the way a new industrial model can change inhabitants' way of life and living conditions (Fox 2015). In RDM, social aspects will be mainly defined by the new role of the customer in the supply chain (Fox, 
2014). End users will have more power, as they will be able to co-create and co-design their products. RDM will also improve the relationship between the manufacturer and the consumer. Social challenges, opportunities and research questions identified are described below.

- The social opportunities in the current timeframe (2017) relate to enhanced customer interactions in the democratisation of product/service development. At the moment, the industry is seeing more co-design activities in which the user takes an active participation in the design and manufacturing of goods. This enables local and global enterprises to create a community sense. However, at the same time, the consumer goods industry is facing more pressure to deliver an excellent experience as with social media bad reputation can significantly impact an organisation. To capitalise better from these social media opportunities, some changes in industrial practices are needed. These changes include a better integration between retailers and suppliers and viewing competitors as collaborators. However, at the moment these changes are challenging to implement.

- In the near future (2025), social opportunities are related to enhancing skills in local communities, better access to knowledge through sharing platforms, enhanced transparency in the supply chain, as well as better work-life balance by changing how products and services are produced, sold and delivered. The challenges identifies are related to the mechanisms for sharing knowledge and skills as well as to the willingness to share information by companies. Therefore, a key question to answer is what are the networks and social connections needed to respond appropriately to the demands of sharing knowledge and skills. 
- In the distant future (2035), the main opportunity is a full democratisation of production systems. However, the challenge remains in the transition to this democratisation and the role that education has to play to acquire the right skills and knowledge to minimise the effects of technology on employment. 


\section{Technological Aspects}

Technological factors are related to the technological advances and new ways for transferring information using big data and the IoT. Current trends have seen the advantage of using these technologies to enable more connected manufacturing systems. These advantages include having the capacity to address the increasingly complex consumer goods' supply chain by integrating information and knowledge between producers, suppliers and consumers (Faller and Feldmuller 2015). The challenges, opportunities and research questions identified for technological aspects are described below.

- Current (2017) advances in technology have seen improvements in manufacturing processes as well as the creation of new enhanced processes due to automation, data capture and data analysis. These improvements have enabled opportunities for traceability of materials and products within the supply chain up to the retail floor as well as improvements in the delivery of services. For $\mathrm{RDM}$, this means that proximity of manufacturing systems to the retail shop could be even more manageable. However, to have a cross-functional communication system, there are still some challenges to overcome including cyber security, and management of big data.

- In the near future (2025), a more dynamic and interactive system could be seen, in which RDM operates within a mass production system enabled by technological advances. This could bring opportunities to scale up additive manufacturing processes, optimise the amount of materials used and create new business models. To enable this dynamic and interactive system of manufacture, accurate management and analysis of big data would be needed. Thus, future 
challenges are related to the integration and protection of data as well as issues related to ownership and democratisation of data.

- In the distant future (2035), opportunities for redistribution of consumer goods would be enabled by a fully automated system, which can self-repair, selfoperate and self-diagnose. However, this raises questions on the capabilities of machine learning, infrastructural changes as well as the scale in which these technologies will need to operate.

\section{Legal Aspects}

Legal aspects mainly imply new laws and regulations due to new attitudes and approaches from government (Srdjevic et al. 2012). It is the most important aspect to move towards an RDM model enabled by digital technologies as at the moment only a limited regulation exists concerning the ethics and use of big data (Gray and Thorpe 2015). As such, a number of opportunities, challenges and research questions relate to this aspect.

- In the current timeframe (2017), it is necessary to change existing laws on the rights and use of land for small scale factories as well as there are opportunities to re-think the current laws on rights and duties for the use of data collected by services.

- In the near future (2025), changes in local legislation enabled by the redistribution of production and consumption systems could create opportunities to decrease export and import costs. Legal challenges, such as protection of intellectual property and brands as well as sharing of data, would need to be addressed in near future where mass-customisation is the norm in a redistributed model. In addition, increased competition at local markets could be challenging 
to control and legislate. Thus, a question to answer is what policy framework for governments; regions and other parties are needed to control unfair competition, and to enable fair management of data.

- A legal opportunity for the distant future (2035) is the regulation of democratisation of designs related to intellectual property rights. However, to start thinking about the legislative framework, it is important to ask questions on how this democratisation would look like.

\section{Environmental Aspects}

Finally, environmental aspects are related to the management of natural resources and potential environmental impacts (Srdjevic et al. 2012). To set the vision of RDM, environmental aspects are linked to new logistics management related to the emergence of small and local factories for the consumer goods sector. In addition, other aspects are considered such as the optimisation of the amount of material used through the introduction of services and the use of material available locally, as described below.

- In the current timeframe (2017), environmental opportunities for RDM are related to the improvement of waste management through applying strategies of repair, reuse and recycle, as well as reduction of emissions through the reduction of transport. However, a question still remains if lower scale production systems could drive environmental sustainability.

- In the near future (2025), the main challenge for RDM would be to prove its positive impact on the environment by addressing the following questions: a) what is the percentage of transport reduced through the adoption of an RDM model, b) could we better engage with users to encourage them to return unwanted items to be reuses, repaired, remanufactured or recycled, and c) what 
is the environmental impact of managing resource flows for long and short life products.

- In the distant future (2035), the opportunity for RDM is to generate an industrial system that is dynamic and sustainable.

\section{Discussion: The vision of redistributed manufacture for the UK's consumer goods industry}

The roadmap helped to identify four RDM characteristics to define the vision of Redistributed model of production and consumption for the UK's consumer goods industry. It was seen that political, economic, social, technological, legal and environmental aspects are closely related to each other. As such, four characteristics were deduced from the opportunities and challenges and possible research questions, to understand the changes needed to achieve this vision. These characteristics are:

\section{Customisation}

Customisation is driven directly by the customer, and it is an on-going trend in our current society (Fox 2014). From the findings it was deduced that, in social terms, customisation is moving to enable customers to take part in the design and the production of goods thanks to the integration of big data and the IoT with automated systems such as additive manufacturing. This is already happening in the food industry. For example, mymuesly.com ${ }^{4}$ is a small scale production of cereals where consumers can create their own personalised muesli package with machine to machine communication (Mosterman and Zander 2016, Moreno and Charnley 2016).

\footnotetext{
${ }^{4}$ German company that allow customers to personalise their own cereals boxes.
} 
Moreno and Charnley (2016) argue that in economic terms, companies will increase their profits in the long term through a better understanding of their consumers, improving their brands and their relationship with their customers. However, the findings revealed that this would require adjusting the role of retailers, and that customisation will be at the cost of exorbitant prices. Interviewees also acknowledge that in the distant future customisation could have competitive prices, so economically up to then it will make sense.

Due to technological advancements, the findings revealed that customisation is about creating versatility and an unlimited variety of product that can be made locally. Customisation also brings the opportunity to create modular products depending on the customers' needs. As a result, the product is made of the exact features desired by the users, optimising the amount of material needed, having a potential to reduce environmental impacts. Dickens et al. (2013) argue that in the next 20 years, technological advancements will have a big social impact as products will be manufactured based on personal data. This will drive a new set of legislations in the near future that will foster local economic growth.

\section{Use of digital technologies}

Technologically, the future will be driven more and more by robotics and automation. It will evolve step-by-step, starting with the improvement of human-to-machine communication and then, moving to a total machine-to-machine communication (Verma et al. 2016). The findings estimated that in 35 years, we will see the evolution of self-configuring production with self-repairing, self-operating and self-diagnostics systems that will make certain goods (such as consumer appliances and electronics) being repaired automatically (Dickens et al. 2013). 
Interviewees acknowledged that the shift to full automation will require high investments for companies and an important change in the way we work. As, such they do not foresee this happening soon. The biggest barrier will be the social transition to a fully automated consumer goods industry, as works may resist to this transition (FasthBerglund and Stahre 2013).

Emerging technologies such as additive manufacturing will bring economic and environmental benefits, as seen in some complex products in aerospace and biotechnology (Pancost and McMahon 2015). However, the findings revealed that now and in the near future additive manufacture will be only used to produce some parts of a product rather than a product in its whole due to efficiency and costs. The findings also revealed that additive manufacturing could reduce environmental impacts, as it's process is based on the optimisation of materials used (Despeisse et al., 2016). The findings of this research also pointed out that additive manufacturing will help to decrease carbon emissions due to transportation of goods, as products will be produced locally and in-situ.

The use of additive manufacturing in the consumer goods sector is very challenging, and not very applicable as the industry is not yet ready to apply it on a large scale. However, the findings also revealed that 3D printing hubs would be more common to print certain personal products, bringing a social change, as consumers will be closer to the production process and, better understanding the requirements to produce goods.

The use of big data for manufacturing processes is becoming very important for the consumer goods sector, as producers are starting to capitalise on the use of big data to drive their design and innovation processes (Baur and Wee, 2015). Findings revealed that the sector is starting to realise the economic opportunities big data could bring, in 
terms of increase competitiveness, deliver of new products and services, improvement of production and improved relationships with customers as well as delivering products in a shorter time scale.

To better capitalise on the use of data, companies need to create a digital trust by ensuring effective and reliable data protection. According to the findings, big data and the Internet are two important aspects of RDM, where there are currently no clear regulations and rights. As such putting in place regulations that could enable better control of the data will increase trust of manufacturers (Nanterme and Daugherty, 2016).

\section{Local Production}

Local production could enable smaller, low-cost and more flexible factories closer to the customer, which could offer economic and social benefits in terms of low capital investment that could impact society in general. For instance, with the use of

technology, the same product could be produced in different places, enabled by additive manufacturing (Chen and Tsai, 2016).

The shift towards a more localised production of consumer goods will need new policies and regulation for small and large manufacturers, as well as better support for start-ups. Better regulations and support in the UK could generate economic growth, employment, drive innovation and improve productivity and performance (OECD, 2016).

According to the findings, new taxation regulations could be implemented to drive re-distribution of the consumer goods sector. This could include for example lower taxes for those that assemble or produce the final product closer to their customers. This could be possible as from a legal point of view, today factories and companies' location depend on the taxes applied in each territory. As such, the UK 
government could set up free tax locations to encourage local manufacturing hubs. However, this should take the amount of resource available on each part of the country into consideration and make sure enough resources are available to respond to customer's demands (Rauch et al., 2016).

Local production will also enable shortening of the supply chain. The number of semi-finished to finished products shipped will be significantly reduced (Rauch et al., 2016). For instance, the use of emerging technologies could allow a reduction of the number of logistic stages from 8 to 4 in short distance transport (Ferdinand et al., 2016). Producing locally will also reduce the delivery time to the final user, satisfying both manufacturers and consumers. Economically, autonomous production could increase the European GDP to $11 \%$ by 2035 and reduce the UK's trade deficit by a third (Ellen MacArthur Foundation, 2015). The socio-technological challenge though, both for industries and customers, is to re-think the way to product and assemble, apply efficient cross-functional communication, opt for fully flexible and efficient processes that haven't change for one hundred years and, link together infrastructures, software, intellectual property, liability, transactional conditions, and social protocols.

In general re-distribution of the consumer goods sector could bring socioeconomic benefits including reduction of high cost production and overproduction, improve relationships between customers and manufacturers, use local material and expertise, meet consumer needs more effectively, improve flexibility and delivery times, and create new jobs (Matt et al., 2015). For example, in the UK the number of microbreweries increased significantly over the last few years which created an economic boost and a significant increase in the number of local jobs for young people with 869,000 new jobs (Department for Communities and Local Government, 2015). 


\section{Development of new business models}

Redistributed models of production and consumption could help to develop new business models based on the delivery of services (Srai et al., 2016, Stahel, 2016). Examples of services within the production of goods already exist in the consumer goods industry. An example of this in the UK is Graze ${ }^{5}$ which offer a service to customise snacks; and Vitsoe ${ }^{6}$ who offers a maintenance and installation service for the furniture they produce (Moreno and Charnley, 2016). With the development of new business models based on servitisation, companies in the consumer goods sector have the economic opportunity to reduce their stocks, optimise the use and availability of existing products, and possibly postpone their end-of-life (Ferdinand et al., 2016, Rauch et al., 2016).

In addition, open innovation has opened the possibility to develop new business models. The social trend of "Do It Yourself" is currently growing, based mainly on the growth of social networks and the emergence of 'Fablabs and Maker- spaces ${ }^{7}$ (Prendeville et al., 2015). Some manufacturers such as Open Desk ${ }^{3}$ have capitalised on this, as they sell files of open source designs to let customers produce their own furniture in such spaces. This type of business model could enable time savings in getting products to market (Waller and Fawcett, 2014). The socio-economic and technological challenge is to enrol all sub-sectors of the consumer goods industry to

\footnotetext{
${ }^{5}$ Manufacturer of personalised snacks boxes with a subscription.

${ }^{6}$ Furniture manufacturer.

${ }^{7}$ Small communities where people share their « Do-It-Yourself » skills or their inspiration with other makers to make or repair items. A Fab-lab usually takes advantage of digital tools
} (Kohtala 2014). 
capitalise from open source designs and sharing information. If this happens, it is predicted that it will be in the next 25 to 35 years, central and connected spaces that serve as knowledge hubs could emerge (Dickens et al., 2013). In addition, these new business models have to be based on a system that balances the self-interest of people involved and the possible sustainability impacts (Antikainen and Valkokari, 2016).

\section{Comparison with previous research}

The most recent research on opportunities and challenges of RDM was conducted by Srai et al. (2016), who also identified key characteristics related to RDM. These characteristics are digitalisation, personalisation, new enabling technologies and enhanced user and producer participation. We recognised their proximity to the characteristics identified through the presented study. In addition, we also acknowledge that RDM characteristics in both studies could be intertwined with each other and could act as enablers for further features. For example, customisation is a direct consequence of the use of digital technologies. Because the proximity between characteristics, we considered new enabling technologies and digitalisation as a single characteristic referred to in this paper as the use of digital technologies, as digitalisation with the use of new technologies will allowed manufacturing to happen at any time and in any location (Rauch et al., 2016).

Srai et al. (2016) also identified specific opportunities and challenges for RDM. However, their scope is more generic as their analysis was based on a cross-case study analysis of different sectors. The challenges and opportunities identified in this paper are exclusively for the consumer goods sector. However, this does not mean that there are not crossovers with other sectors previously studied. For example, in terms of enabling production technologies and infrastructure, both studies acknowledged that the transition towards RDM would depend on the development of new skills, research and 
development and having the right infrastructure in place. In addition, regulatory measures are acknowledged in both studies as an important element, specifically for coordination and governance, intellectual property, and regulatory measures for production in urban landscapes. Moreover, Srai et al. (2016), Rauch et al. (2015, 2016), Matt et al. (2015), Kohtala (2015), Zanetti et al. (2015) and DeVor et al. (2012) acknowledged similar sustainability implications, as the ones presented in this study. Finally, Srai et al. (2016) mentioned the development of new business models as part of the transformational changes in a multi-sector approach. However, this was found to be the biggest challenge for the consumer goods sector, as this industry hasn't changed in the last 30 years (Chatterjee et al., 2010). The roadmap developed acknowledged this, and despite the fact that some transformations are happening now, a full transition will take between 25 and 35 years to be realised.

\section{Conclusions}

The aim of this research was to explore the challenges, opportunities and future research questions to set a vision of redistributed manufacturing for the UK's consumer goods industry. Through this paper, it was seen that the re-distribution of manufacturing for the consumer goods sector is in its infancy in the UK setting. However, current socioeconomic and technological trends could assist in the transition towards RDM in this specific sector. If RDM is to happen in the future, the entire supply chain will need to be re-designed with new interactions between customers, suppliers and manufacturers. Customers will have a significant role in the next industrial model, which will allow economic growth for companies and more choice and satisfaction for customers. However, challenges still need to be addressed. Uncertainties concerning the ability of customers to be engaged in RDM still exist and more research on customers' behaviours and motivations to be conducted to realise whether or not RDM attracts only a niche 
market. Further research is also needed to determine the exact impacts RDM has on supply chains transcending UK's borders.

According to the current discourse between academics and industry experts, an innovation roadmap is attained to set a first vision of RDM for the UK's consumer goods sector. However, implementing this vision is complex and needs further research. This is because all aspects studied are intertwined and could change rapidly according to their different influences. As such, for the purpose of this study we only aimed to foresee the emerging trends and characteristics that can enable or inhibit RDM in this specific sector and context. However, further research needs to be conducted to understand the impacts of global trends, such as changing demographics, greater urbanisation, increased automation, environmental regulation and shift towards a sharing economy, on implementing a redistributed model of consumption and production. In addition, as the consumer goods sector is broad, it is recommended to consider sub-sectors in future research.

This enquiry was based on experts' opinions from different backgrounds to set a vision. However, the authors acknowledge that further research needs to be conducted to understand how the devolved trends as well as global trends could influence RDM. For example, increase in technology and automation are global trends but also emerge as trends to consider as part of the RDM movement. A further analysis of these trends could help the research on identified opportunities, challenges and research questions.

\section{Acknowledgements}

This research was funded by the Engineering and Physical Sciences Research Council (EPSRC) grant (EP/017567/1) as part of the Network on Redistributed Manufacturing, Consumer Goods and Big Data (RECODE Network). We thank all the participants that took part in the workshops and interviews conducted for this research. 


\section{References}

Antikainen Maria and Valkokari Katri. 2016. "A Framework for Sustainable Circular Business Model Innovation” Technology Innovation Management Review, 5(7): $1-65$.

Beamon Benita M. and Fernandes Clara. 2004. "Supply-chain network configuration for product recovery." Planning, Production and Control 15(3): 270-281.

Baur Cornelius and Wee Dominik. 2015. "Manufacturing's next act." McKinsey and Company, June. Accessed: 31 May 2016. http://www.mckinsey.com/businessfunctions/operations/our-insights/manufacturings- next-act.

Birtchnell Thomas and Urry John. 2016. A New Industrial Future? 3D Printing and the Reconfiguring of Production, Distribution and Consumption. London and New York: Routledge.

Chartterjee Ishan, Küpper Jörn, Mariager Christian, Moore Patrick and Steve Reis. 2010. "The decade ahead: Trends that will shape the consumer goods industry." Consumer Packaged Goods Practice. McKinsey and Company. London, UK.

Chen Toly and Tsai Horng-Ren. 2016. "Ubiquitous manufacturing: Current practices, challenges, and opportunities." Robotics and Computer-Integrated Manufacturing, 45: 126-132.

Department for Communities, Local Government. 2015. "Britain becomes 'brewing powerhouse'.” UK Government, August 11. Accessed 30 July 2016. https://www.gov.uk/government/news/britain-becomes-brewing-powerhouse

Despeisse Melanie, Baumers Martin, Brown Phil, Charnley Fiona, Ford Simon, Garmulewicz Alysia, et al. (2016). "Unlocking value for a circular economy through 3D printing: a research agenda." International Journal Technological Forecasting and Social Change, 115: 75-84

DeVor Richard E., Kapoor Shiv G., Cao J., Ehmann Kornel F. 2012. "Transforming the landscape of manufacturing: distributed manufacturing based on desktop manufacturing (DM).” Journal of Manufacturing Science Engineering, 134(4): 041004.

Dickens Phil, Kelly Michael and Williams John R. 2013. "What are the significant trends shaping technology relevant to manufacturing?" Foresight Government Office for Science, Future of Manufacturing Project, Evidence Paper 6.

Ellen MacArthur Foundation. 2015. Towards a circular economy: business rationale for an accelerated transition. Cowes, UK. 
Fasth-Berglund Åsa and Stahre Johan. 2013. "Cognitive automation strategy for reconfigurable and sustainable assembly systems." Assembly Automation 33(3): $294-303$.

Ferdinand Jan-Peter, Flämig Heike, Petschow Ulrich, Steinfeldt Michael and Worobei Anton. 2016. The Decentralized and Networked Future of Value Creation. 3D printing and its implications for society, industry and sustainable development. Progress in IS, edited by: Ferdinand, Petschow, Dickel, 205-236. Switzerland: Springer International Publishing.

Fogliatto Flavio S., da Silveira Giovanni J.C., Borenstein Denis. 2012. "The mass customization decade: An updated review of the literature." International Journal of Production Economics, (138): 14-25.

Foresight. 2013. The Future of Manufacturing: A new era of opportunity and challenge for the UK Project Report. London: Government Office of Science.

Fox Stephen. 2014. "Third Wave Do-It-Yourself (DIY): Potential for prosumption, innovation, and entrepreneurship by local populations in regions without industrial manufacturing infrastructure", Technology in Society (39): 18-30.

Fox Stephen. 2015. "Moveable factories: How to enable sustainable widespread manufacturing by local people in regions without manufacturing skills and infrastructure." Technology in Society (42): 49-60.

Freeman Rachel, McMahon Chris and Godfrey Patrick. 2015. "Design of an integrated assessment of Redistributed manufacturing for the sustainable, resilient city." In Smart Innovation, Systems and Technologies: Proceedings of the Third International Conference on Sustainable Design and Manufacturing (SDM-16), edited by Setchi, Howlett, Liu, Theobald, 601-612. Switzerland: Springer International Publishing.

Gandhi Suketu and Erik Gervet. 2016. "Internet of Things and Product Design." MIT Sloan Management Review. Accessed 19 Sept. 2016. Available at: http://sloanreview.mit.edu/article/internet-of-things-and-product-design/

Gao Weiwei, Zhanga Yunbo, Ramanujana Devarajan, Ramania Karthik, Chen Yon, Williams Christopher B., Wang Charlie C.L., Shin Yung C., Zhang Song and Zavattier Pablo D. 2015. "The status, challenges, and future of additive manufacturing in engineering." Computer-Aided Design (69): 65-89.

Garetti Marco, Taisch, M. 2012. "Sustainable manufacturing: trends and research challenges." Production Planning \& Control: The Management of Operations, 23(2-3): 83-104. 
Genovese Andrea, Lenny Koh, S.C., Kumar, Niraj, Tripathi, Pradhumm Kumar. 2014. "Exploring the challenges in implementing supplier environmental performance measurement models: A case study". Planning Production and Control 25:11981211

Gibson Ian, Rosen David W. and Stucker Brent. 2009. Additive Manufacturing Technologies: Rapid Prototyping to Direct Digital Manufacturing s[s: Springer.

Gray Elizabeth Alexandra and Jane Hyatt Thorpe. 2015. "Comparative effectiveness research and big data: balancing potential with legal and ethical considerations." Journal of Comparative Effectiveness Research 4 (1): 61-74.

Kang Ling, Wang Shilong and Li Changsong. 2016. "Cloud Manufacturing ServiceOriented Platform for Group Enterprises." In Smart Innovation, Systems and Technologies: Proceedings of the Third International Conference on Sustainable Design and Manufacturing (SDM-16), edited by Setchi, Howlett, Liu, Theobald, 649-671. Switzerland: Springer International Publishing.

Kietzmann Jan, Pitt Leyland, Berthon Pierre. 2014. "Disruptions, decisions, and destinations: Enter the age of 3-D printing and additive manufacturing". Business Horizons, (58): 209-215.

Kohtala Cindy. 2014. "Addressing sustainability in research on distributed production: an integrated literature review." Journal of Cleaner Production (106): 654-668.

Kohtala Cindy and Hyysalo Sampsa. 2015. "Anticipated environmental sustainability of personal fabrication." Journal of Cleaner Production (99): 333-344.

Kostakis Vasilis, Roos Andreas, Bauwens Michel. 2016. "Towards a political ecology of the digital economy: Socio- environmental implications of two competing value models.", Environmental Innovation and Societal Transitions (18): 82100.

Kostoff, R.N. and Schaller, R.R., 2001. Science and technology roadmaps. IEEE Transactions on engineering management, 48(2), pp.132-143.

Liu Peng, Huang Samuel H., Mokasdar Abhiram, Zhou Heng and Hou Liang. 2014. "The impact of additive manufacturing in the aircraft spare parts supply chain: supply chain operation reference (scor) model based analysis." Production Planning \& Control: The Management of Operations (25): 13-14, 1169-1181.

Matt Dominik T., Rauch Erwin and Dallasega Patrick. 2015. "Trends towards Distributed Manufacturing Systems and modern forms for their design." Paper presented at the 9th CIRP Conference on Intelligent Computation in Manufacturing Engineering, 23-25, Capri, July 2014. 
Mintel Report 2016. Footwear Retailing - UK. Mintel. UK.

Malak Derya, Dhillon Harpreet S. and Andrews Jeffrey G. 2016. "Optimizing Data Aggregation for Uplink Machine-to-Machine Communication Networks." IEEE Transactions on communications 64(3): 1274-1290.

Manyika James, Chui Michael, Brown Brad, Bughin Jacques, Dobbs Richard, Roxburgh Charles, Hung Byers Angela. 2011. "Big data: The next frontier for innovation, competition, and productivity." McKinsey Global Institute.

Moreno Mariale and Charnley Fiona. 2015. "Can Redistributed manufacturing and digital intelligence enable a regenerative economy? An integrative literature review." In Smart Innovation, Systems and Technologies: Proceedings of the Third International Conference on Sustainable Design and Manufacturing (SDM-16), edited by Setchi, Howlett, Liu, Theobald, 563-575. Switzerland: Springer International Publishing.

Mosterman Pieter J. and, Zander Justyna. 2016. "Industry 4.0 as a Cyber-Physical System study." Softward System Model (15): 17-29.

Mourtzis Dimitris and Doukas Michael. 2013. "Decentralized Manufacturing Systems Review: Challenges and Outlook.” Robust Manufacturing Control (355): 355367.

Nanterme Pierre and Daugherty Paul. 2016. The Technology Vision 2016 - People First: The Primacy of People in a Digital Age. Accenture.

OECD. 2016. “United Kingdom.” Accessed: 31 May 2016. https://data.oecd.org/unitedkingdom.htm\#profile-agriculture

Pancost Rich and McMahon Chris. 2015. "Manufacturing in Bristol - Bridging the gap to a more sustainable and more resilient future." Accessed 21 May 2016. http://cabot- institute.blogspot.co.uk/2015/04/manufacturing-in-bristol-bridginggap.html

Prendeville Sharon, Hartung Grit, Purvis Erica, Brass Clare and Hall Ashley. 2016. "Makespaces: From Redistributed Manufacturing to a Circular Economy." In Smart Innovation, Systems and Technologies: Proceedings of the Third International Conference on Sustainable Design and Manufacturing (SDM-16), edited by Setchi, Howlett, Liu, Theobald, 577-588. Switzerland: Springer International Publishing.

Rauch, Erwni, Dallinger Matthias, Dallasega, Patrick, Matt, DominikT. 2015. "Sustainability in manufacturing through distributed manufacturing systems (DMS)." Procedia CIRP, (29): 544-549. 
Rauch Erwin, Dallinger Matthias, Dallasega Patrick, Matt, Dominik T. 2016.

"Sustainable production in emerging markets through Distributed Manufacturing Systems (DMS)" Journal of Cleaner Production, (135): 127-138.

Robson Colin. (2002) Real world research. UK: Blackwell Publishing.

Romero, D., Molina, A., 2011. Collaborative networked organisations and customer communities: Value co-creation and co-innovation in the networking era. Production Planning and Control 12 (5-6):447-472.

Smith, Stephen F. 1992. Knowledge-based production management: Approaches, results and prospects. Planning, Production and Control 3(4): 350-380.

Srai Jagjit Singh, Kumar Mukesh, Graham Gary, Phillips Wendy, Tooze James, Tiwari Ashutosh, Ford Simon, Beecher Paul, Raj Baldev, Gregory Mike, Tiwari Kumar Manoj, Ravi B., Neely Andy, Shankar Ravi. 2016. "Distributed manufacturing: scope, challenges and opportunities." International Journal of Production Research.

Srdjevic Zorica, Bajcetic Ratko and Srdjevic Bojan. 2012. "Identifying the Criteria Set for Multi-criteria Decision Making Based on SWOT/PESTLE Analysis: A Case Study of Reconstructing A Water Intake Structure.” Water Resources

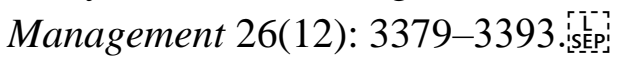

Stahel Walter R. 2016. “The circular economy.” Accessed 18 May 2016. http://www.nature.com/news/the-circular-economy-1.19594? WT.mc_id=FBK_SB_NNews_0216

Sternberg Elaine. 2015. “Defining capitalism.” Economic affairs, 35(3): 380-396.

Vega-Jurado Jaider, Juliao-Esparragoza David and D.Paternina-Arboleda Carlos D. 2015. "Integrating Technology, Management and Marketing Innovation through Open Innovation Models.” Journal of Technology Management \& Innovation, 10(4): 85-90.

Verma Pawan Kumar, Verma Rajesh, Prakash Arun, Agrawal Ashish, Naik Kshirasagar, Tripathi Rajeev, Alsabaan Maazen, Khalifa Tarek, Abdelkader Tamer and Abogharaf Abdulhakim. 2016. "Machine-to-Machine (M2M) communications: A survey." Journal of Network and Computer Applications, (66): 83-105.

Waller Matthew A. and Fawcett, Stanley E. 2014. "Click Here to Print a Maker Movement Supply Chain: How Invention and Entrepreneurship Will Disrupt Supply Chain Design." Journal of Business Logistics.

Zanetti Cristiano, Seregni Marco, Bianchini Massimo and Taisch Marco. 2015. “A 
production system model for Mini-Factories and last mile production approach." Paper presented at the $1^{\text {st }}$ International Forum on Research and Technologies for Society and Industry Leveraging a better tomorrow (RTSI), Torino, 16-1. 